\title{
The effect of local pressure in diphtheritic neuropathy
}

\author{
A. P. HOPKINS AND J. A. MORGAN-HUGHES \\ From the Institute of Neurology, The National Hospital, Queen Square, London
}

Conduction studies in certain human neuropathies have shown that electrophysiological changes are sometimes confined to, or are more marked at, sites where pressure palsies commonly occur in otherwise healthy subjects. For example, Mulder, Lambert, Bastron, and Sprague (1961) found delayed conduction in the median nerve below the wrist in over $8 \%$ of a large group of unselected diabetic patients. Gilliatt and Willison (1962), in a smaller series, described five diabetic patients with isolated peripheral nerve lesions involving the median nerve at the wrist, the ulnar nerve at the elbow, and the lateral popliteal nerve. Essentially similar findings have also been encountered in the GuillainBarré syndrome (Lambert and Mulder, 1964), and in the familial neuropathy described by Earl, Fullerton, Wakefield, and Schutta (1964). These observations in man have led to the suggestion that peripheral nerves which are minimally affected by disease may be rendered more susceptible to the effects of repeated minor trauma, traction, or mechanical compression.

In a recent study of experimentally induced diphtheritic neuropathy in caged guinea-pigs (Morgan-Hughes, 1965a), a lesion in the plantar nerves of the hind-foot was encountered which appeared to provide a model of the localized lesions sometimes seen in the human neuropathies described above. Since healthy guinea-pigs which are housed for prolonged periods in cages with wiremesh flooring are known to develop a pressure lesion of the plantar nerves (Fullerton and Gilliatt, 1965), it was suggested that the lesion which occurred in diphtheritic animals after a much shorter period was due to the combined effects of diphtheria toxin and mechanical compression from the floor of the cage (Morgan-Hughes, 1965b).

In order to test this hypothesis, a series of experiments has now been conducted to investigate the role of weight bearing in the pathogenesis of this lesion.

\section{MATERIAL AND METHODS}

All experiments were carried out on healthy male and female guinea-pigs aged between 12 and 20 weeks. The animals were reared to this age in large pens with solid floors covered with a thick layer of sawdust.

Diphtheritic neuropathy was produced by subcutaneous injection of mixtures of partially neutralized diphtheria toxin and antitoxin as described by McDonald (1963). The dose of excess toxin required to produce a neuropathy varied from 0.95 to $5.01 . \mathrm{f}$./u./kg in different animals according to the duration of storage of the toxin.

Guinea-pigs were fed on a standard pellet diet (Short and Gammage, 1959) supplemented by fresh green vegetables.

The animals were divided into four groups:

Group 1 Guinea-pigs transferred after injection of toxin to cages with wire-mesh floors similar to those used by Fullerton and Gilliatt (1965). The clinical illness in these animals and the electrophysiological and histological changes in the nerves of the thigh and leg have already been described in detail elsewhere (MorganHughes, 1965a, 1968).

Group 2 Guinea-pigs caged as in group 1; in these animals conduction velocity and the histological findings in the anterior tibial nerve were also studied. This nerve supplies, through its terminal branches, the short extensor muscle on the dorsum of the hind-foot, and is therefore not exposed to pressure from the floor of the cage.

Group 3 Animals transferred after injection of toxin to cages with solid floors covered with a deep layer of soft sawdust and studied in the same way as those of the first two groups.

Group 4 Guinea-pigs suspended in their cages so that the hind-feet did not touch the floor of the cage for up to 10 weeks after injection of diphtheria toxin. Suspension was by means of broad webbing straps, individually fitted to each animal. All four limbs hung free. The front limbs rested on the food box in the cage so that considerable movement of the body was possible, although the hind limbs could not touch any part of the cage. Food and water could be taken freely. Two guineapigs were suspended without a previous injection of diphtheria toxin and both maintained their weight for three months.

ELECTROPHYSIOLOGICAL METHODS Conduction velocity in the motor fibres of the anterior and posterior tibial nerves was estimated in anaesthetized animals using a method similar to that of Kaeser and Lambert (1962). The proximal stimulating cathode was a needle placed close to the sciatic nerve near the hip, and the distal stimulating cathode a clip over the anterior or posterior tibial nerve at the ankle. The active recording electrode 
was a needle which just pierced the skin over the belly of the short extensor muscle on the dorsum of the foot for the anterior tibial nerve and over the lateral interosseous muscle of the sole for the posterior tibial nerve. The remote electrode was another needle placed into the skin of one of the digits. A third needle over the lateral malleolus acted as a ground electrode. The stimulus for the belly-tendon recordings was always supramaximal; when measuring the distal latency the shortest value was always taken. Conduction in single motor nerve fibres was also studied by recording individual motor-unit action potentials through a double-core needle electrode (Disa 13K80) using weak stimuli. Further details of the methods are given by Morgan-Hughes (1968).

HISTOLOGICAL METHODS Nerves from the hind-limbs were carefully removed, laid on card and fixed in $10 \%$ formol-saline or Flemming's solution. Those fixed in formol-saline were stained with $1 \%$ osmium tetroxide and teased apart in glycerine according to the method described by Vizoso and Young (1948), so that single nerve fibres could be examined. Nerves fixed in Flemming's solution were embedded in paraffin, sectioned at $5 \mu$, and stained with a modification of Weigert's method to show the myelin sheath (Gutmann and Sanders, 1943).

\section{RESULTS}

HEALTHY GUINEA-PIGS Normal values for maximal motor conduction velocity and for distal latency in the anterior and posterior tibial nerves of 34 healthy animals aged between 12 and 20 weeks and reared in large pens with solid floors are summarized in Table I. It can be seen from this table that the maximal velocity in the motor fibres of the posterior and anterior tibial nerves was similar. The shorter distal latency for the anterior tibial nerve reflects the shorter distance from the distal stimulating cathode to the muscle.

GUINEA-PIGS INJECTED WITH DIPHTHERIA TOXIN Illustrative recordings from the plantar muscles of one injected guinea-pig kept on wire mesh are seen in Fig. 1. Figure 1a shows the recordings obtained
TABLE I

CONDUCTION VELOCITY AND DISTAL LATENCY BEFORE THE INJECTION OF DIPHTHERIA TOXIN

\begin{tabular}{lcccc}
\hline & $\begin{array}{c}\text { Observations } \\
(\text { no. })\end{array}$ & $\begin{array}{c}\text { Mean } \\
(\mathrm{msec})\end{array}$ & $\begin{array}{c}S . \mathrm{D} . \\
(\mathrm{msec})\end{array}$ & $\begin{array}{c}\text { Range } \\
(\mathrm{msec})\end{array}$ \\
\cline { 2 - 5 } & 66 & 1.64 & 0.16 & $1 \cdot 3-2 \cdot 2$ \\
$\begin{array}{l}\text { Posterior tibial, } \\
\text { distal latency }\end{array}$ & 64 & $\begin{array}{c}1.00 \\
\mathrm{~m} / \mathrm{sec}\end{array}$ & $\begin{array}{c}0 \cdot 14 \\
\mathrm{~m} / \mathrm{sec}\end{array}$ & $\begin{array}{c}0.8-1 \cdot 5 \\
\mathrm{~m} / \mathrm{sec}\end{array}$ \\
$\begin{array}{l}\text { Anterior tibial, } \\
\text { distal latency }\end{array}$ & 65 & 48.0 & 3.68 & $41-58$ \\
$\begin{array}{l}\text { Posterior tibial, } \\
\text { Conduction velocity }\end{array}$ & 60 & 48.3 & 3.49 & $41-56$ \\
$\begin{array}{l}\text { Anterior tibial, } \\
\text { conduction velocity }\end{array}$ & & & & \\
\hline
\end{tabular}

before the injection of diphtheria toxin. The distal latency from the ankle was $2 \cdot 2 \mathrm{msec}$, and the conduction time from hip to ankle was $1.4 \mathrm{msec}$. Thirty days after injection (Fig. 1b), at a time when the animal had a clinical neuropathy, the amplitudes of the muscle action potentials had decreased and the conduction time in the thigh and leg had increased from 1.4 to $1.8 \mathrm{msec}$, although the distal latency remained within the normal range. However, by the 76th day (Fig. 1c) the distal latency had increased to $3.7 \mathrm{msec}$, conduction time in the thigh and leg having returned to normal. This illustrates that conduction in the plantar nerve may be impaired at a time when the same fibres in the leg have recovered.

GROUP 1 Serial measurements of conduction velocity and distal latency in the motor fibres supplying the plantar muscles in the sole of the hind-foot were carried out on 21 injected guineapigs which survived the clinical illness, and a further 10 animals which failed to develop any clinical evidence of a neuropathy. In Table II the animals have been grouped according to the severity of the clinical illness (see Morgan-Hughes, 1968). The results have been divided into those recorded
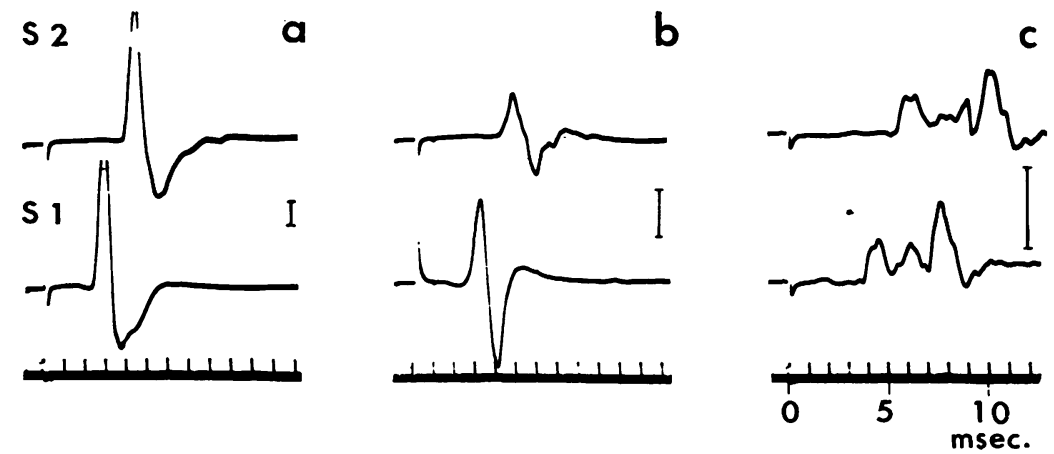

FIG. 1. G-P. D13

Illustrative belly-tendon records from the posterior tibial nerve and plantar muscles of a moderately affected animal (a) before the injection of toxin, (b) after 30 days, (c) after 76 days. $S_{1}-$ stimulation at ankle; $S_{\mathbf{2}}$-stimulation at hip. Calibration-1mV. 
TABLE II

DISTAL LATENCY AND CONDUCTION VELOCITY IN THE POSTERIOR TIBIAL NERVES OF GROUP 1 DIPHTHERITIC GUINEA-PIGS, CAGED ON WIRE MESH

\begin{tabular}{|c|c|c|c|c|c|c|c|c|c|}
\hline \multirow[b]{3}{*}{ Animals } & \multirow[b]{3}{*}{ (no.) } & \multicolumn{4}{|c|}{18 to 47 days after injection } & \multicolumn{4}{|c|}{48 to 85 days after injection } \\
\hline & & \multicolumn{2}{|c|}{$\begin{array}{c}\text { Distal latency } \\
\text { (msec) }\end{array}$} & \multicolumn{2}{|c|}{$\begin{array}{c}\begin{array}{c}\text { Conduction } \\
\text { velocity }\end{array} \\
\quad(\mathrm{m} / \mathrm{sec})\end{array}$} & \multicolumn{2}{|c|}{$\begin{array}{c}\text { Distal latency } \\
\text { (msec) }\end{array}$} & \multicolumn{2}{|c|}{$\begin{array}{c}\begin{array}{c}\text { Conduction } \\
\text { velocity }\end{array} \\
(\mathrm{m} / \mathrm{sec})\end{array}$} \\
\hline & & Range & Mean & Range & Mean & Range & Mean & Range & Mean \\
\hline \multirow{4}{*}{$\begin{array}{l}\text { Severely } \\
\text { affected } \\
\text { Moderately } \\
\text { affected } \\
\text { Mildly } \\
\text { affected } \\
\text { No clinical } \\
\text { illness }\end{array}$} & 5 & $1 \cdot 7-2 \cdot 6$ & $2 \cdot 20$ & $10-33$ & $21 \cdot 4$ & $2 \cdot 8 \cdot 13 \cdot 0$ & $6 \cdot 50$ & $12-32$ & $23 \cdot 4$ \\
\hline & 4 & $2 \cdot 1-2 \cdot 4$ & $2 \cdot 20$ & $26-45$ & $33 \cdot 5$ & $3 \cdot 8-5 \cdot 0$ & $4 \cdot 35$ & 29.37 & $31 \cdot 5$ \\
\hline & 12 & $1 \cdot 5-2 \cdot 8$ & $2 \cdot 02$ & $28-52$ & $41 \cdot 7$ & $1 \cdot 8-7 \cdot 0$ & $3 \cdot 62$ & $30-52$ & $40 \cdot 6$ \\
\hline & 10 & & & & & $2 \cdot 0-4 \cdot 7$ & 3.07 & $25-48$ & $39 \cdot 0$ \\
\hline
\end{tabular}

during the clinical illness (which ranged from 18 to 47 days in different animals) and those recorded after clinical recovery. The figures refer to the longest distal latency recorded in each animal and to conduction velocity in the leg obtained on the same day. Supramaximal shocks were applied to the nerve, the muscle action potentials being recorded through belly-tendon electrodes.

Distal latency increased beyond the normal range in less than one-third of the animals examined during the clinical illness in spite of profound slowing of conduction in the thigh and leg. Values greater than $2.2 \mathrm{msec}$ were recorded in only four out of nine guinea-pigs with moderate or severe paralysis and in only two out of 12 in which the clinical illness was mild. The longest latencies recorded during the clinical illness ranged from 1.7 to $2.6 \mathrm{msec}$ (mean $2.2 \mathrm{msec}$ ) in severely paralysed animals, from 2.1 to $2.4 \mathrm{msec}$ (mean $2.2 \mathrm{msec}$ ) in the moderately affected group, and from 1.5 to 2.8 msec (mean $2.0 \mathrm{msec}$ ) in the mildly affected group.

However, later observations on these animals showed that the distal latency continued to increase after recovery from the clinical illness, the highest values being obtained between 48 and 85 days after inoculation. This was in contrast to conduction in the motor fibres in the thigh and leg, for in over half $(57 \%)$ of these animals conduction velocity in this part of the nerve was already beginning to return to normal. The longest latencies were recorded in those animals which had shown the greatest reduction in maximal velocity in the thigh and leg during the acute illness. In the five guinea-pigs which had recovered from severe paralysis, the longest latencies ranged from 2.8 to $13.0 \mathrm{msec}$ with a mean of $6.50 \mathrm{msec}$. In moderately affected and mildly affected animals, the longest latencies recorded after clinical recovery ranged from 3.8 to
$5.5 \mathrm{msec}$ (mean $4.35 \mathrm{msec}$ ) and from 1.8 to 7.0 msec (mean $3.62 \mathrm{msec}$ ) respectively.

A lesser increase in distal latency was also seen in nine out of 10 guinea-pigs which failed to develop any evidence of a clinical illness. The longest latencies, which were recorded between 50 and 80 days after injection ranged from 2.0 to $4.7 \mathrm{msec}$ with a mean of $3.07 \mathrm{msec}$.

The relation between the changes in distal latency and the changes in conduction in the thigh and leg is illustrated in Fig. 2, which shows the results of serial observations on 21 guinea-pigs which survived for not less than 90 days after inoculation. Thirteen of these animals showed clinical evidence of a neuropathy and eight remained clinically normal. It can be seen from Fig. 2 that, in this group of animals, maximal slowing of conduction in the leg occurred between 40 and 50 days after injection. Although slowing of conduction in this part of the nerve occurred earlier in many severely paralysed animals (Morgan-Hughes, 1968), it must be remembered that few of these survived long enough to be included in Fig. 2. However, in spite of the relatively late changes in conduction in the thigh and leg, the distal latency was increasing in these animals at a time when conduction in the thigh and leg was already beginning to return to normal.

The distal latency returned to within the normal range in 13 out of 15 guinea-pigs which were studied between 100 and 200 days after injection of toxin. In one animal, which had recovered from a severe illness, the distal latency was $2.7 \mathrm{msec} 300$ days after injection. A second animal, which had recovered from a moderate illness, was killed for histological study 180 days after inoculation when the distal latency was $2.3 \mathrm{msec}$. In general the reduction of the distal latency was accompanied by a gradual decrease in temporal dispersion of the 


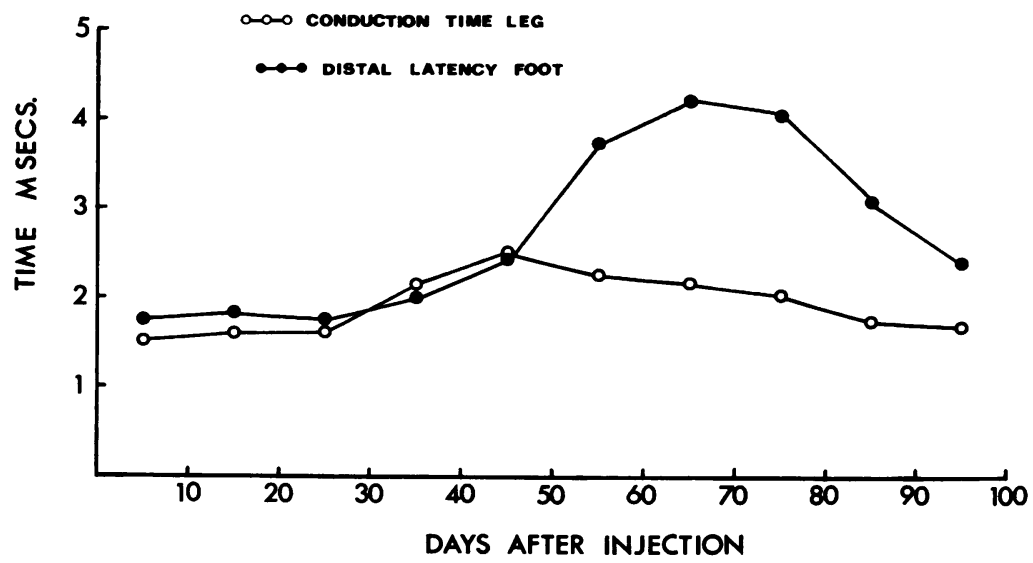

FIG. 2. The mean values for conduction time between hip and ankle (open circles), and for distal latency (filled circles) in the posterior tibial nerve of 21 guinea-pigs which survived for not less than 90 days after injection of diphtheria toxin. Mean values have been calculated from results grouped in 10-day intervals after injection.

muscle action potential, a finding illustrated in Fig. 3. Although three mildly affected and one unaffected guinea-pig showed only minor changes in the latency measured to the earliest deflection of the muscle action potential, it was possible to identify late components in the dispersed muscle response. The upper tracings in Fig. 4 are the belly-tendon records from a mildly affected animal, 56 days after injection. It can be seen that with supramaximal stimulation the latency to the earliest deflection of the muscle action potential measured $2 \cdot 1 \mathrm{msec}$ from the ankle and $3.7 \mathrm{msec}$ from the hip, conduction velocity in the leg being $44 \mathrm{~m} / \mathrm{sec}$. However, the late components, marked $a$ and $b$ in Fig. 4, have distal latencies measured to peaks of $8.4 \mathrm{msec}$ and
$10 \cdot 3 \mathrm{msec}$ respectively, velocities in the leg being 44 and $37 \mathrm{~m} / \mathrm{sec}$.

After the upper recordings in Fig. 4 had been obtained, a double core needle electrode was inserted into the plantar muscles of the sole and the nerve was stimulated with weak shocks so that single motor units could be identified. An example is shown in the lower part of Fig. 4, where the late component (c) has a latency of $12.3 \mathrm{msec}$ from the ankle and $14.4 \mathrm{msec}$ from the hip, velocity in the thigh and leg being $33 \mathrm{~m} / \mathrm{sec}$. Single units with prolonged distal latencies are rarely found in normal animals (Fullerton and Gilliatt, 1967) but were present in all our group 1 animals, including those which were clinically unaffected.
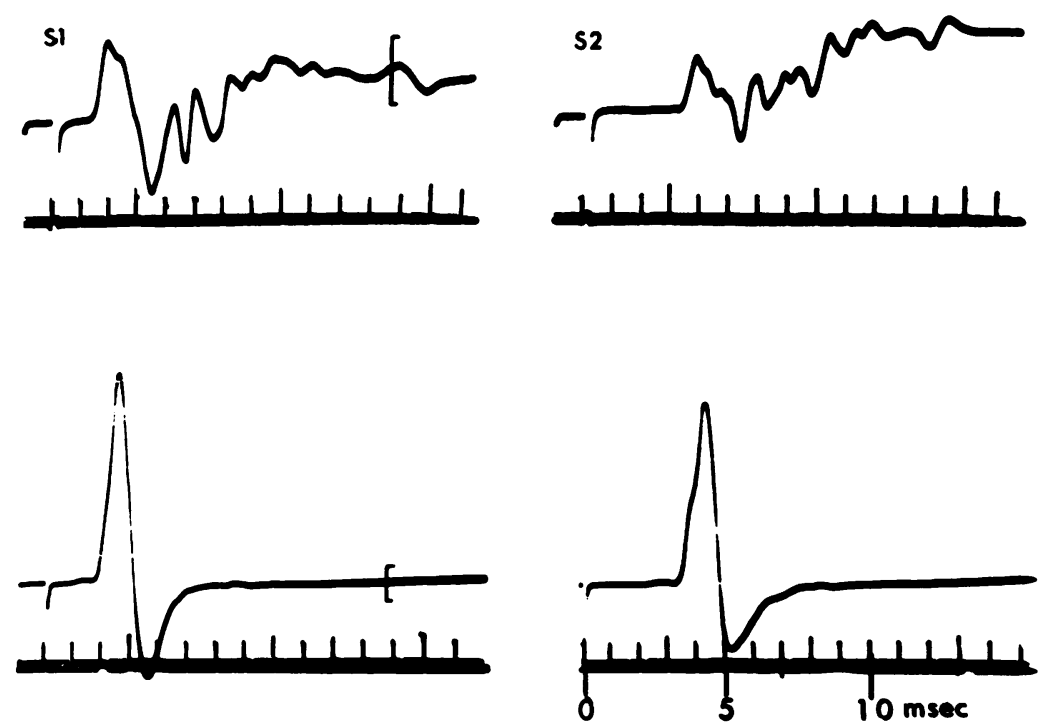

FIG. 3. G-P. M43 Bellytendon records from the plantar muscles of a clinically unaffected guinea-pig to show temporal dispersion of the muscle action potential 52 days after toxin (upper records), and recovery by 170 days (lower records). $S_{1}$-stimulation at ankle; $S_{2}-$ stimulation at hip. Calibration-l $\mathrm{mV}$. 

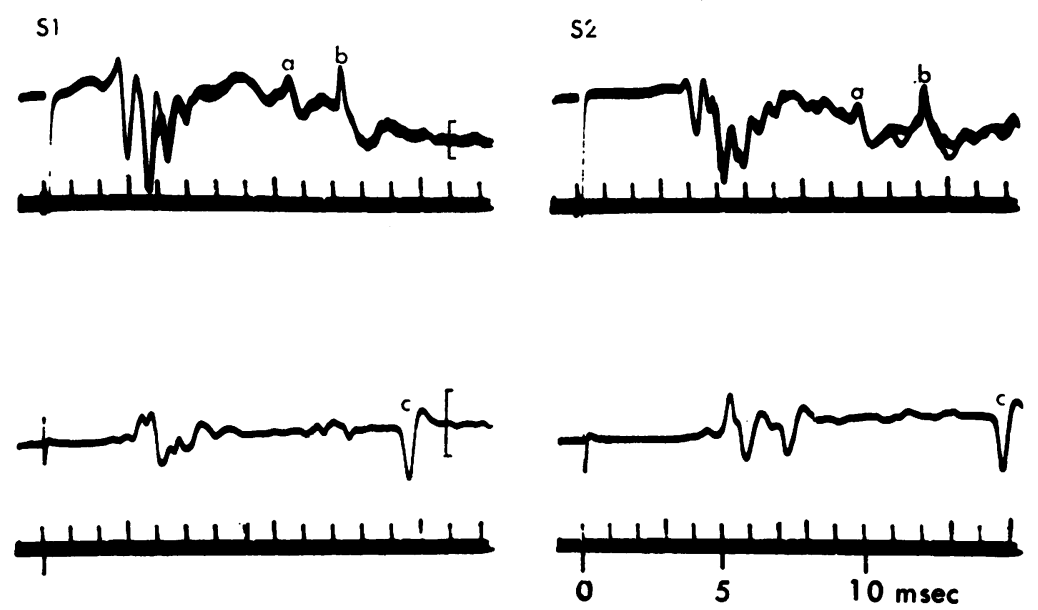

FIG. 4. G-P. M51 Records

from the plantar muscles of $a$ mildly affected guinea-pig to show motor unit action potentials $(a-c)$ with prolonged distal latencies. Top-belly-tendon records; bottom-recorded through a double-core needle electrode. $S_{1}$-stimulation at ankle; $S_{2}-$ stimulation at hip. Calibration$500 \mathrm{~V}$.

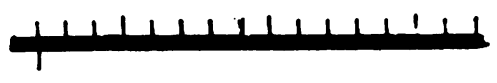

GROUP 2 Thirteen out of 15 injected guinea-pigs in this group survived for at least 70 days after injection. Ten animals developed a characteristic clinical illness. Conduction was studied serially in both the anterior tibial nerve supplying the extensor digitorum brevis muscle on the dorsum of the hind-foot, and in the posterior tibial nerve, supplying the plantar muscles of the sole. The lowest velocity recorded on any occasion in the posterior tibial nerve ranged from 15 to $50 \mathrm{~m} / \mathrm{sec}$, with a mean of 35.7. Similar velocities were recorded from the anterior tibial nerve, where the lowest velocity ranged from 6 to $50 \mathrm{~m} / \mathrm{sec}$, with a mean of 34.2. However, serial recordings carried out on this group of animals showed that the marked slowing of conduction in the plantar nerve in the sole was not accompanied by a comparable change in the terminal part of the anterior tibial nerve. The longest distal latency in the posterior tibial nerve ranged from 2.2 to $5.5 \mathrm{msec}$ (mean $3.37 \mathrm{msec}$ ), and in the anterior tibial nerve from 1.0 to 1.7 msec (mean $1.28 \mathrm{msec}$ ).
The results of serial observations on one animal in this group are illustrated in Fig. 5. There is a slight increase in conduction time in the thigh and leg for both the anterior and posterior tibial nerves. However, the marked increase in the posterior tibial distal latency to $4 \cdot 1 \mathrm{msec} 61$ days after injection, is not seen in the anterior tibial nerve, where the longest distal latency was only $1.3 \mathrm{msec}$.

GROUP 3 In contrast with the findings in healthy guinea-pigs (Fullerton and Gilliatt, 1967), caging on soft sawdust failed to prevent the prolongation of the distal latency in diphtheritic animals. All 10 animals in this group developed a clinical illness and in five conduction was studied for at least 59 days after injection of diphtheria toxin. The lowest velocity in the posterior tibial nerve ranged from 16 to $34 \mathrm{~m} / \mathrm{sec}$, with a mean of 23.8 , and in the anterior tibial nerve from 17 to $32 \mathrm{~m} / \mathrm{sec}$, with a mean of 25.4 . The longest distal latency in the posterior tibial nerve ranged from $2 \cdot 3$ to $8.0 \mathrm{msec}$ (mean $4.34 \mathrm{msec}$ ), and in the anterior
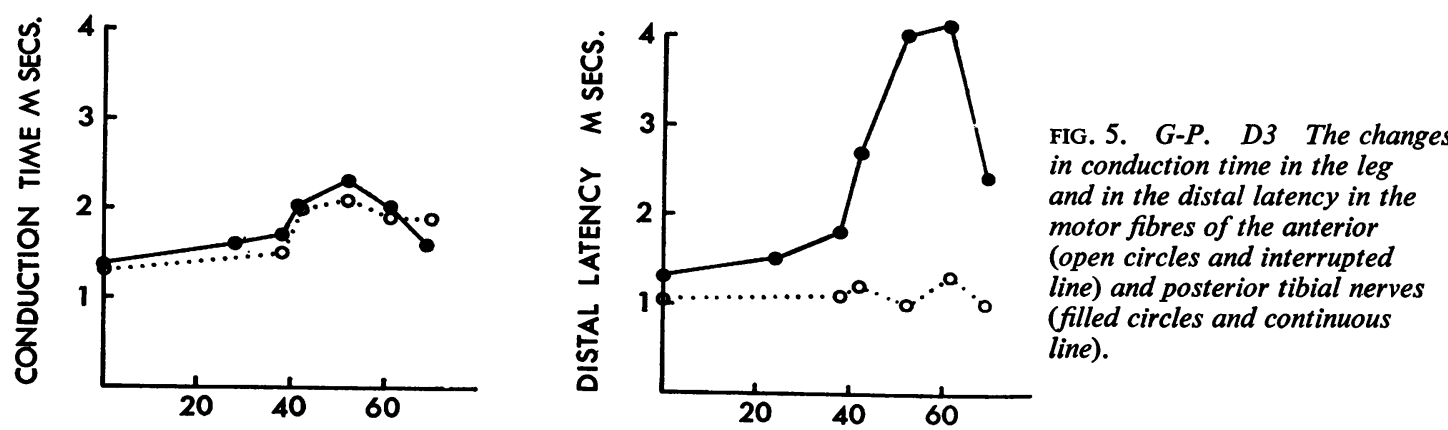

DAYS AFTER INJECTION 
tibial nerve from 1.3 to $1.5 \mathrm{msec}$ (mean $1.42 \mathrm{msec}$ ).

It was always possible to identify late components in the dispersed muscle action potential from the plantar muscles in the same way as in the animals of group 1.

GROUP 4 Eight injected guinea-pigs were suspended in slings for at least 63 days after the injection of diphtheria toxin. A further group of 18 guinea-pigs was injected at the same time as the suspended animals, using similar doses from the same batch of toxin, and caged on wire. The suspended group and the weight-bearing group were examined at about the 60 th day, conduction velocity being estimated in the posterior tibial nerves of both hindlimbs. The recording from one hind-limb of one suspended animal was discarded for technical reasons. Fifteen records were selected from the injected weight-bearing group in which the conduction velocities between thigh and ankle matched those of the suspended animals. The distal latencies for the two groups were then compared. The results are shown in Table III. The mean conduction velocity in both weight-bearing and suspended animals fell by about $10 \mathrm{~m} / \mathrm{sec}$. The mean distal latency for the weight-bearing animals was $3.44 \mathrm{msec}$ (range 1.6 to $7.9 \mathrm{msec}$ ), but for the suspended animals was only $1.87 \mathrm{msec}$ (range 1.3 to $2.3 \mathrm{msec}$ ). Moreover, careful exploration of the plantar muscles in the suspended animals, using a double core needle electrode, failed to reveal any motor units with prolonged distal latencies such as were always found in weight-bearing animals.

\section{TABLE III}

DISTAL LATENCY AND CONDUCTION VELOCITY IN THE POSTERIOR TIBIAL NERVES OF WEIGHT-BEARING AND SUSPENDED ANIMALS 60 DAYS AFTER THE INJECTION OF DIPHTHERIA TOXIN

\begin{tabular}{clccc}
\hline & & $\begin{array}{c}\text { Nerves } \\
\text { examined }\end{array}$ & $\begin{array}{c}\text { Conduction } \\
\text { velocity }\end{array}$ & $\begin{array}{c}\text { Distal } \\
\text { latency }\end{array}$ \\
\cline { 3 - 5 } Weight-bearing & Mean & & $(\mathrm{m} / \mathrm{sec})$ & $(\mathrm{msec})$ \\
\cline { 3 - 5 } & Range & 15 & $39 \cdot 6$ & $3 \cdot 44$ \\
& S.D. & & $31-47$ & $1 \cdot 6-7 \cdot 9$ \\
& Mean & & $5 \cdot 5$ & $1 \cdot 61$ \\
Controls & Range & 15 & $38 \cdot 7$ & $1 \cdot 87$ \\
(no toxin) & S.D. & & $31-47$ & $1 \cdot 3-2 \cdot 3$ \\
& Mean & & $4 \cdot 4$ & $0 \cdot 22$ \\
& Range & 65 & 48.0 & $1 \cdot 64$ \\
& S.D. & & $41-58$ & $1 \cdot 3-2 \cdot 2$ \\
& & & $3 \cdot 7$ & $0 \cdot 16$ \\
\hline
\end{tabular}

*Control animals as in Table I.

Figure $6 \mathrm{a}$ and $\mathrm{b}$ summarizes the results obtained in groups 2, 3 and in the suspended animals of group 4. The longest distal latency recorded from both the anterior and posterior tibial nerves in each animal of groups 2 and 3 during the first 40 days of intoxication has been plotted against the conduction time from hip to ankle recorded on the same day (open symbols). The increase in conduction time in the thigh and leg is accompanied by a small but proportionate increase in distal latency for both the anterior (Fig. 6a) and the posterior (Fig. 6b) tibial nerves. However, if the longest distal latencies in the same animals recorded later than 40 days after injection of diphtheria toxin are plotted against the corresponding conduction time in thigh and leg, there is a disproportionate increase in distal latency in the posterior tibial nerve (Fig. 6b, filled symbols). This finding is not seen in the anterior tibial nerve(Fig. 6a, filled symbols), where there are only slight changes in distal latency. The disproportionate changes in posterior distal latency seen in the weight-bearing groups are not encountered in guinea-pigs suspended throughout the period of observation, indicated by crosses in Fig. 6 b.

Observations on three guinea-pigs which were suspended for different periods after inoculation with toxin suggest that weight-bearing during the first three to four weeks after injection may be critical for the development of the plantar nerve lesion. For example, one animal which was suspended for the first $\mathbf{3 0}$ days and then placed on wire for a further 38 days was found to have a distal latency of $1.9 \mathrm{msec} 65$ days after injection, although conduction velocity in the leg had fallen to $29 \mathrm{~m} / \mathrm{sec}$. Furthermore, exploration with a double-core needle electrode failed to reveal any late units in this animal. However, a second guinea-pig suspended for only 21 days after injection and then kept on wire for a further 47 days was found to have several motor units with latencies from the ankle of up to $10 \cdot 2$ msec, although the latency to the earliest deflection of the muscle action potential remained normal at $1.8 \mathrm{msec}$; conduction velocity in the thigh and leg of this animal was $31 \mathrm{~m} / \mathrm{sec}$. A third guinea-pig which was caged on wire for the first 23 days and then suspended for the next 35 days developed a characteristic lesion of the plantar nerve. Examination on the 58th day revealed a posterior tibial nerve distal latency of $4.7 \mathrm{msec}$, conduction velocity in the leg being $28 \mathrm{~m} / \mathrm{sec}$.

HISTOLOGICAL ReSUlts Peripheral nerves from 30 weight-bearing animals and eight suspended guineapigs were examined histologically using teased fibre preparations and sectioned material stained to show the myelin sheath.

The changes in the thigh and leg in both the weight-bearing and suspended animals (groups 2, 3, 


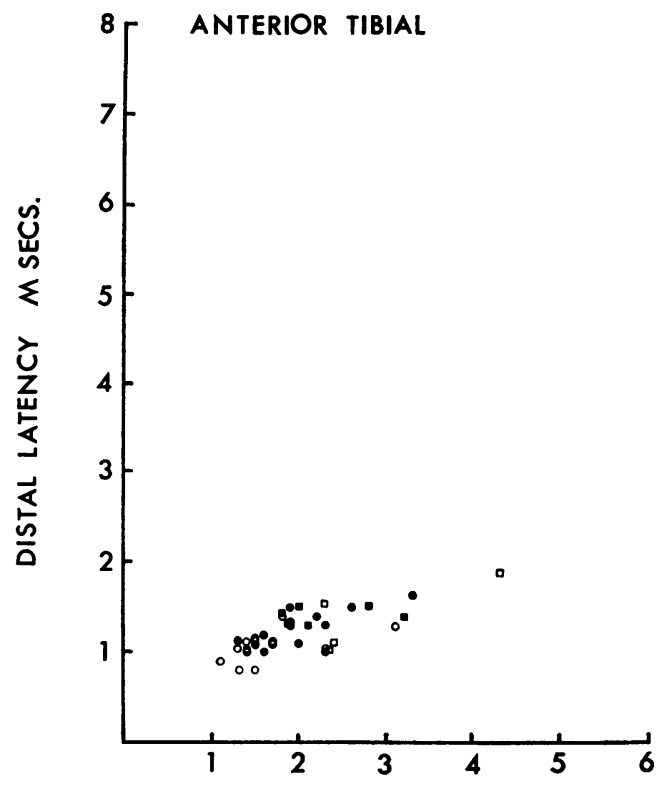

CONDUCTION TIME FROM HIP TO ANKLE

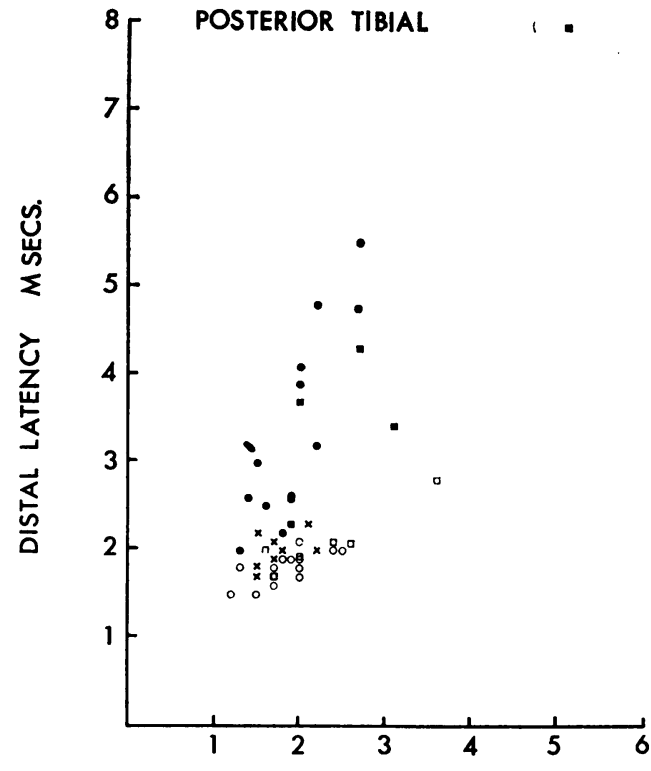

CONDUCTION TIME FROM HIP TO ANKLE

FIG. 6 a.

M SECS.

FIG. $6 \mathrm{~b}$.

M SECS.

FIG. 6. To show the relationship between conduction time in the leg and distal latency in the motor fibres of the anterior (6a) and posterior tibial nerves (6b). The longest distal latency recorded before and after 40 days in each 0 animal has been plotted against the conduction time from hip to ankle recorded on the same day. Open symbols represent the values obtained before 40 days; filled symbols represent values obtained after 40 days. $\bigcirc \bigcirc$-group animals (caged on wire). $\square \square$-group 3 animals (caged on sawdust). $\times$-group 4 animals (suspended).

and 4) were similar to those described previously (Morgan-Hughes, 1965a and 1968) and consisted of patchy demyelination which apparently began at the nodes of Ranvier and later involved complete internodal segments. Recovery from the clinical illness was accompanied by remyelination of affected segments. These changes in the thigh and leg were more marked in severely paralysed animals, and were associated with axonal degeneration in some fibres.

In weight-bearing animals examined between 50 and 80 days after injection, the plantar nerves in the sole of the hind-foot were always more severely affected than those on the dorsum of the foot and in the thigh and leg. The changes in the plantar nerves were characterized by extensive demyelination which was most marked at about the middle of the foot where the majority of the fibres were affected. In this region loss of myelin occurred over several consecutive internodal segments (Fig. 7) and the myelin which remained was often swollen and irregular in appearance. Closer to the ankle, demyelination was often confined to the paranodal regions where short intercalated segments of newly formed myelin were frequently encountered. Occasional fibres in the plantar nerves also showed evidence of axonal degeneration, although the number was small. These changes were in contrast with the findings in the leg and on the dorsum of the foot, where demyelination affected only a small proportion of the fibres in any one area of nerve and rarely involved more than two adjacent internodes in the same fibre.

In animals examined between 50 and 70 days after inoculation, remyelination of affected internodes was usually well established in the leg and on the dorsum of the hind-foot, whereas in the plantar nerves remyelination was unusual at this time. However, in animals killed between the 150th and 250th days, the majority of the fibres from the sole showed evidence of remyelination.

In contrast with the findings in weight-bearing animals, the changes in the plantar nerves of suspended guinea-pigs were essentially similar to the changes encountered on the dorsum of the foot and in the thigh and leg. Segmental demyelination tended to be patchy and rarely affected consecutive internodes in the same fibre. Irregularities of the myelin 


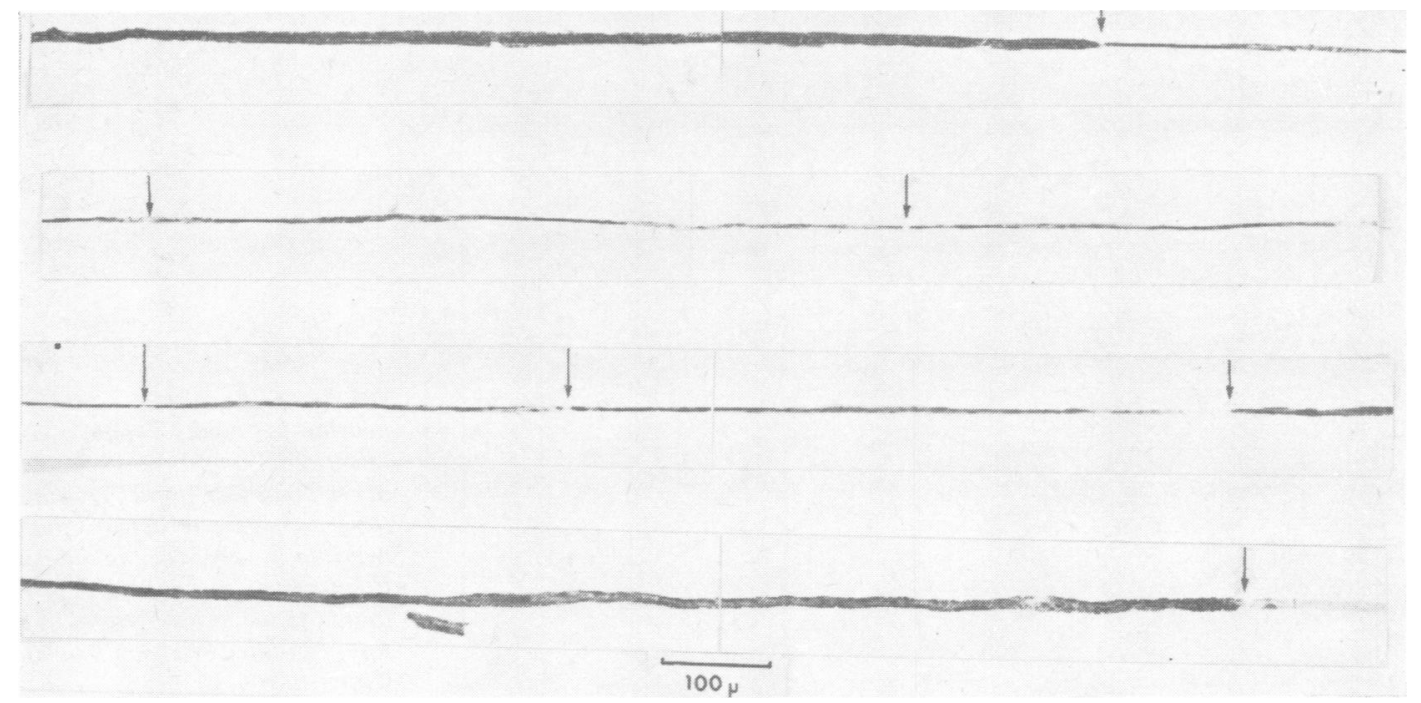

FIG. 7. G-P. D3 Eighty-one days after injection. Consecutive lengths of a single nerve fibre from the plantar nerve. Arrows indicate the nodes of Ranvier. $1 \%$ osmium tetroxide.

and demyelination of consecutive internodes, characteristic findings in the plantar nerves of weightbearing guinea-pigs, were not seen in suspended animals.

The findings in teased fibre preparations were confirmed in transverse sections of whole nerve stained to show the myelin sheath. Transverse sections of the posterior and anterior tibial nerves in their lower thirds, the plantar nerve in the midfoot and the anterior tibial nerve on the dorsum of the hind-foot are shown in Fig. 8. These sections were taken from a guinea-pig which had been caged for 92 days after injection. The slight reduction in the density of myelinated fibres in the anterior and posterior tibial nerves due to diphtheria toxin contrasts sharply with the much more marked reduction in the density of myelinated fibres in the plantar nerve.

\section{DISCUSSION}

The results of the present study support the hypothesis that the lesion encountered in the plantar nerves of diphtheritic guinea-pigs is due to the combined effects of diphtheria toxin and mechanical compression from the floor of the cage. Observations on both weight-bearing and suspended guineapigs have shown that the lesion does not occur in response to diphtheria toxin alone, nor in response to weight-bearing alone.

The lesion in diphtheritic animals differs in several important respects from that described by
Fullerton and Gilliatt $(1965,1967)$ in healthy guinea-pigs. First, it occurs during the first few weeks after caging, whereas the lesion in healthy animals takes several months to develop. Moreover, the lesion in diphtheritic animals is invariably more severe. With supramaximal stimulation and bellytendon recording, latencies longer than $5 \mathrm{msec}$ were not uncommon in injected animals, even in those which showed no clinical evidence of a neuropathy and only minimal changes in conduction velocity in the thigh and leg. In healthy guineapigs, however, the longest posterior distal latency recorded by Fullerton and Gilliatt (1967) was only $3.2 \mathrm{msec}$. In spite of continued exposure to the effects of pressure from weight-bearing, the distal latency returned to normal in 13 out of 15 of our guinea-pigs which were followed for up to 200 days after injection.

The mechanism by which diphtheria toxin renders the plantar nerves more susceptible to weightbearing is not immediately apparent. Earl et al. (1964) suggested three ways in which peripheral nerves could become unduly sensitive to mechanical trauma or compression. Physical abnormalities, such as hypertrophy, poverty of connective tissue, or increased rigidity, might render the nerve more liable to pressure and angulation. Impaired blood supply might also increase the effect of slight mechanical trauma, as might an intrinsic metabolic disturbance.

The results obtained in the two animals suspended for 21 and 30 days and then caged on wire and in the one animal caged on wire for 23 days and then 


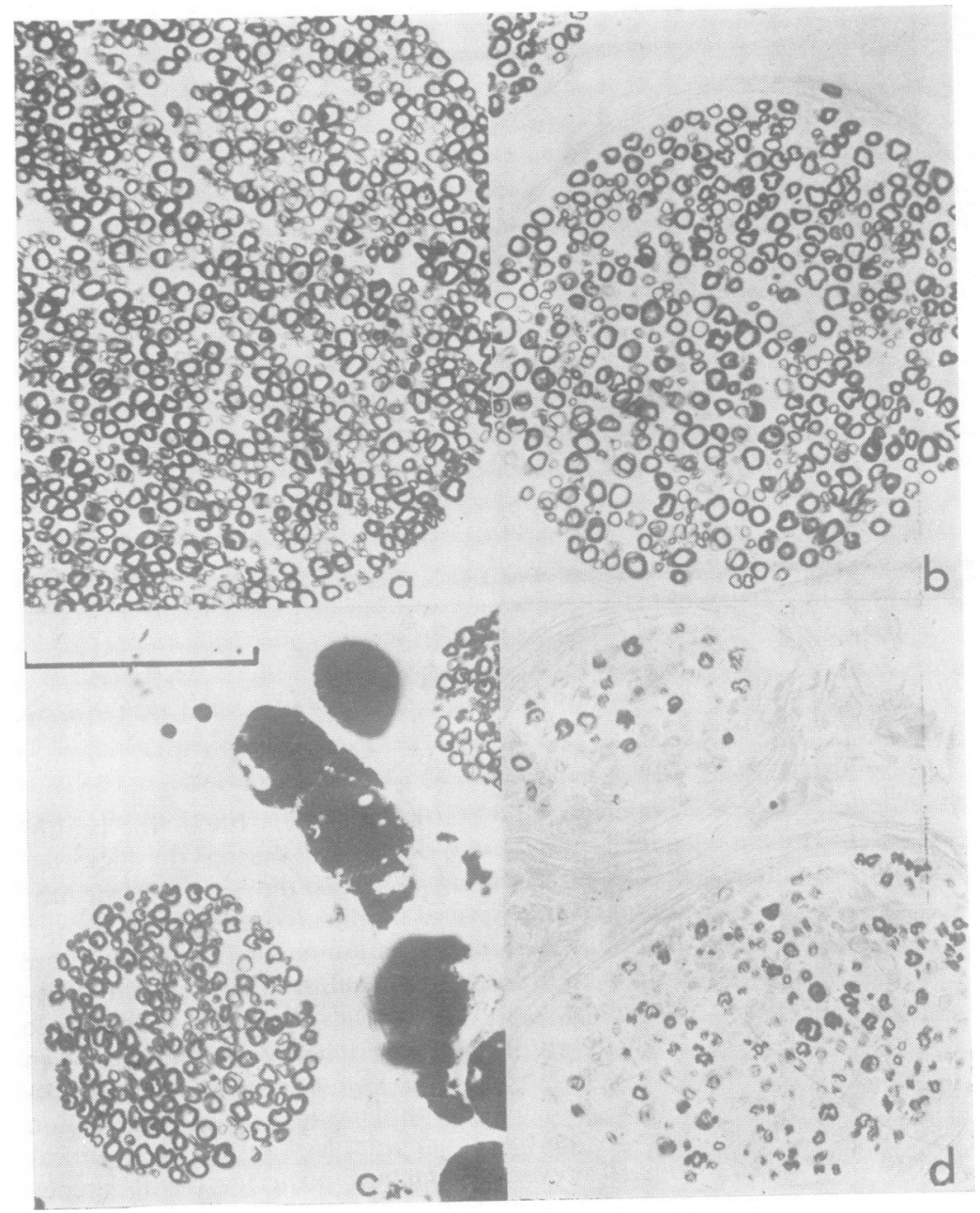

FIG. 8. G-P. D11 Weight

bearing for ninety-two days after injection. Transverse sections of: (a) the anterior tibial nerve in the leg; $(b)$ the posterior tibial nerve in the leg; $(c)$ the anterior tibial nerve on the dorsum of the foot; $(d)$ the plantar nerve in the sole. Modified Weigert's method. Calibration-100 $\mu$.

suspended, suggest that the critical period during which pressure has its effect is within the first three weeks after injection of toxin. Further experiments are necessary to find the critical period within closer limits, but it is clear that the effect may occur before there are any major histological changes in the affected nerves, or any slowing of conduction. It is known that diphtheria toxin interferes with cellular metabolism (Strauss and Hendee, 1959; Collier and Pappenheimer, 1964a, b). Pressure or ischaemia which is also known to produce segmental demyelination (Denny-Brown and Brenner, 1944; Mayer and Denny-Brown, 1964), must in some way accentuate the metabolic disturbance of the Schwann cells in the plantar nerve.

The fact that relatively minor degrees of mechanical trauma can determine the pattern of a peripheral neuropathy in animals may have important clinical implications. Trauma which is not adequate to cause peripheral nerve palsies in healthy subjects may be sufficient to determine the distribution of affected fibres in a human peripheral neuropathy.

\section{SUMMARY}

Electrophysiological and histological studies of experimental diphtheritic neuropathy in the guineapig have shown that animals caged on wire or sawdust develop a lesion of the plantar nerves of the sole of the hind-foot at a time when the motor fibres in the thigh and leg are beginning to recover. $\frac{9}{2}$ As this lesion is not seen in the terminal part of the $D$ anterior tibial nerve, or in the plantar nerves of suspended animals, the observed changes must be $N$ due to the combined effects of toxin and of local pressure or trauma. 
There is some evidence that the critical period for the development of the lesion is within the first three weeks after the injection of toxin, before the appearance of pathological change and of slowing of motor conduction. This lesion may provide an experimental model of those neuropathies, such as diabetes, in which local and generalized factors play a part.

The authors are greatly indebted to Professor R. W. Gilliatt for his encouragement and advice, and to $\mathrm{Dr}$. R. G. Willison for his helpful criticism. We would also like to thank Mr. W. Hinkes for his technical assistance.

\section{REFERENCES}

Collier, R. J., and Pappenheimer, A. M. Jr (1964a). Studies on the mode of action of diphtheria toxin. I. Phosphorylated intermediates in normal and intoxicated Hela cells. J. exp. Med., 120, 1007-1018.

- $120,(1964 \mathrm{~b})$. Studies on the mode of action of diphtheria toxin. II. Effect of toxin on amino acid incorporation in cellfree systems. Ibid., 120, 1019-1039.

Denny-Brown, D., and Brenner, C. (1944). Paralysis of nerve induced by direct pressure and by tourniquet. Arch. Neurol. Psychiat. (Chic.), 51, 1-26.

Earl, C. J., Fullerton, P. M., Wakefield, G. S., and Schutta, H. S. (1964). Hereditary neuropathy, with liability to pressure palsies. Quart. J. Med., 33, 481-498.

Fullerton, P. M., and Gilliatt, R. W. (1965). Changes in nerve conduction in caged guinea-pigs. J. Physiol. (Lond.), 178, 47-48P.
(1967). Pressure neuropathy in the hind-foot of the guineapig. J. Neurol. Neurosurg. Psychiat., 30, 18-25.

Gilliatt, R. W., and Willison, R. G. (1962). Peripheral nerve conduction in diabetic neuropathy. Ibid., 25, 11-18.

Gutmann, E., and Sanders, F. K. (1943). Recovery of fibre numbers and diameters in the regeneration of peripheral nerves. $J$. Physiol. (Lond.), 101, 489-518.

Kaeser, H. E., and Lambert, E. H. (1962). Nerve function studies in experimental polyneuritis, in Progress in Electromyography. Electroenceph. clin. Neurophysiol., Suppl. no 22, 29-35.

Lambert, E. H., and Mulder, D. W. (1964). Nerve conduction in the Guillain-Barré syndrome. Ibid., 17, 86.

Mayer, R. F., and Denny-Brown, D. (1964). Conduction velocity in peripheral nerve during experimental demyelination in the cat. Neurology (Minneap.), 14, 714-726.

McDonald, W. I. (1963). The effects of experimental demyelination on conduction in peripheral nerve: a histological and electrophysiological study. I. Clinical and histological observations. Brain, 86, 481-500.

Morgan-Hughes, J. A. (1965a). Diphtheritic Polyneuritis in the Guinea-pig. M.D. Thesis: University of Cambridge.

- (1965b). Changes in motor nerve conduction velocity in diphtheritic polyneuritis. Riv. Pat. nerve. ment., 86, 253-260.

- (1968). Experimental diphtheritic neuropathy. A pathological and electrophysiological study. J. neurol. Sci., 7, 157-175.

Mulder, D. W., Lambert, E. H., Bastron, J. H., and Sprague, R. G. (1961). The neuropathies associated with diabetes mellitus. A clinical and electromyographic study of 103 unselected diabetic patients. Neurology (Minneap.), 11, 275-284.

Short, D. J., and Gammage, L. (1959). New diet for laboratory animals. Brit. med. J., 1, 511-512.

Strauss, N., and Hendee, E. D. (1959). The effect of diphtheria toxin on the metabolism of HeLa cells. J. exp. Med., 109, 145-163.

Vizoso, A. D., and Young, J. Z. (1948). Internode length and fibre diameter in developing and regenerating nerves. J. Anat. (Lond.), 82, 110-134. 